\title{
Acute gastroenteritis in infants under 6 months old
}

\author{
R Fox, C L S Leen, E M Dunbar, M E Ellis, B K Mandal
}

\begin{abstract}
Sixty two babies under the age of 6 months who were admitted with gastroenteritis completed a study of gradual refeeding compared with abrupt refeeding after a period of rehydration. There was no difference in the incidence of recurrence of diarrhoea due to lactose intolerance, effect on weight, or duration of hospital stay. Twenty six babies (42\%) had recurrence of diarrhoea after refeeding, all of whom settled with the introduction of a lactose free soya based formula. Well nourished babies under 6 months of age with mild to moderately severe gastroenteritis can be fed immediately with full strength milk feeds after rehydration. The introduction of a lactose free soya based preparation may provide an alternative to repeated attempts at regrading with cows' milk feeds in those patients with lactose intolerance.
\end{abstract}

The dietary management of gastroenteritis in infants usually involves a period of starvation and oral or intravenous rehydration followed by gradual reintroduction of milk feeds, a system known as regrading. The principle argument in favour of regrading is the avoidance of the consequences of carbohydrate malabsorption. ${ }^{1}$ Despite early clinical evidence that it is unnecessary $^{2}$ regrading has been seriously questioned only recently. ${ }^{3-5}$ Early reintroduction of full strength feeds (rapid refeeding) is now recommended in patients over 6 months of age, but because data to provide guidance are unavailable, caution is still advised in younger infants. $^{6}$

The use of standardised oral rehydration solutions is widespread in developing countries, ${ }^{7}$ and in the United Kingdom where they are prescribed by general practitioners to $80 \%$ of infants with gastroenteritis. ${ }^{8}$

Carbohydrate malabsorption causes delayed recovery from acute gastroenteritis in infancy, especially in the malnourished ${ }^{9}$ and in those who are very young. ${ }^{10}$ Lactose intolerance is the most common presentation in children under the age of 6 months. ${ }^{11}$ The incidence of lactose intolerance seems to be declining, ${ }^{12}$ so therefore this study was designed to establish whether there is any advantage in gradually refeeding infants under the age of 6 months, with particular reference to (i) recurrence of diarrhoea and lactose intolerance, (ii) effect on weight, and (iii) duration of hospital stay.

Patients and methods

Sixty six babies under 6 months of age who were admitted to this unit with acute gastroenteritis (defined as acute onset of watery or extremely loose diarrhoea with or without vomiting for no more than seven days) were entered into the study between April 1988 and January 1989. Patients were excluded if the diagnosis was thought not to be gastroenteritis or if they were already receiving low lactose preparations for presumed lactose intolerance.

All babies received oral rehydration solution for 12 hours and were then randomly allocated to one of two feeding regimens. The solution used was Dioralyte (Rorer), which provides sodium $35 \mathrm{mmol} / \mathrm{l}$, chloride $37 \mathrm{mmol} / \mathrm{l}$, potassium $20 \mathrm{mmol} / \mathrm{l}$, bicarbonate $18 \mathrm{mmol} / \mathrm{l}$, and glucose $200 \mathrm{mmol} / \mathrm{l}$. Group 1 were gradually refed with their usual cows' milk formula or breast milk at one quarter strength for 12 hours and then half strength for 12 hours, before commencing full strength feeds. Group 2 were immediately fed their usual full strength cows' milk formula or breast milk after a 12 hour period of oral rehydration. Nude weight was recorded on admission and daily thereafter, and percentage weight gain compared between the two groups. Stool frequency and consistency and the presence of blood and mucus were recorded by the nursing staff.

Recurrence of diarrhoea was defined as continued or return of diarrhoea with refeeding. Recurrence was presumed secondary to refeeding if no other cause could be established and lactose intolerance diagnosed if 0.5 to $2 \%$ reducing sugars were present in the stools when tested by Clinitest (Ames). ${ }^{13}$ When recurrence was due to refeeding, the feed was changed to a soya based lactose free formula (Wysoy, Wyeth).

Specimens of the first three stools were cultured for pathogenic bacteria and stained for the presence of cryptosporidia. Viruses were identified (in the admission specimen) by tissue culture in monolayers of $\mathrm{Hep} 2$ cells in addition to examination by electron microscopy after concentration by ultracentrifugation. Enzyme linked immunosorbent assay (ELISA) for rotavirus was not performed.

Informed parental consent was obtained in all cases. The significance of differences were calculated by the $\chi^{2}$ and Mann-Whitney $U$ tests.

\section{Results}

Four patients were subsequently excluded from the study (one patient had bilateral hydronephrosis, one patient had pyloric stenosis, and two patients were discharged by their parents against medical advice). Thus 32 patients in group 1 , and 30 patients in group 2 completed
Correspondence to: Dr Mandal.

Accepted 30 April 1990 
the study. Characteristics of both groups are given in table 1 . There were no significant differences in age, sex, ethnic origin, duration of symptoms, treatment before admission with oral rehydration solution, bottle compared with breast feeding, admission weight, stools in the first 24 hours, or average number of stools per day. All patients had mild or moderately severe gastroenteritis assessed by clinical signs of

Table 1 Patient characteristics. Figures are given as mean (range)

\begin{tabular}{lll}
\hline & $\begin{array}{l}\text { Group } 1 \\
(n=32)\end{array}$ & $\begin{array}{l}\text { Group } 2 \\
(n=30)\end{array}$ \\
\hline $\begin{array}{lll}\text { Age (weeks) } \\
\text { Sex M/F }\end{array}$ & $11 \cdot 5(2-22)$ & $11 \cdot 8(2-24)$ \\
Ethnic origin: & $11 / 21$ & $12 / 18$ \\
$\quad$ White & 26 & 22 \\
$\quad$ Asian & 5 & 7 \\
$\quad$ Mixed & 1 & 1 \\
$\begin{array}{l}\text { Duration of symptoms (days) } \\
\text { Prehospital treatment with }\end{array} \quad 4 \cdot 0(1-7)$ & $3 \cdot 9(1-7)$ \\
oral rehydration solution (days) & 21 & 22 \\
Bottle/breast feeding & $32 / 0$ & $28 / 2$ \\
Admission weight (kg) & $5 \cdot 2(3 \cdot 0-8 \cdot 6)$ & $5 \cdot 2(3 \cdot 1-7 \cdot 3)$ \\
No of stools in first 24 hours & $3 \cdot 0(0-8)$ & $4 \cdot 0(0-7)$ \\
Average stools/day & $2 \cdot 4(0 \cdot 8-5 \cdot 3)$ & $2 \cdot 9(1 \cdot 2-6 \cdot 0)$ \\
Intravenous fluids required & 0 & 0 \\
\hline
\end{tabular}

There were no significant differences.

Table 2 Recurrence of diarrhoea within seven days of refeeding and treated with lactose free soya based formula. Figures are given as number (\%)

\begin{tabular}{|c|c|c|c|}
\hline & $\underset{(n=32)}{\text { Group } 1}$ & $\underset{(n=30)}{\text { Group } 2}$ & \\
\hline $\begin{array}{l}\text { Significant stool sugars } \\
(0.5-2 \cdot 0 \%)\end{array}$ & $10(31)$ & $13(43)$ & $\begin{array}{l}\mathrm{p}>0.1 \\
\left(\chi^{2}=0.969\right)\end{array}$ \\
\hline $\begin{array}{l}\text { No significant stool sugars } \\
\text { No recurrence }\end{array}$ & $\begin{aligned} 3(9) \\
19(60)\end{aligned}$ & $\begin{array}{l}0 \\
17(57)\end{array}$ & $\begin{array}{l}p>0.5 \\
\left(\chi^{2}=0.048\right)\end{array}$ \\
\hline
\end{tabular}

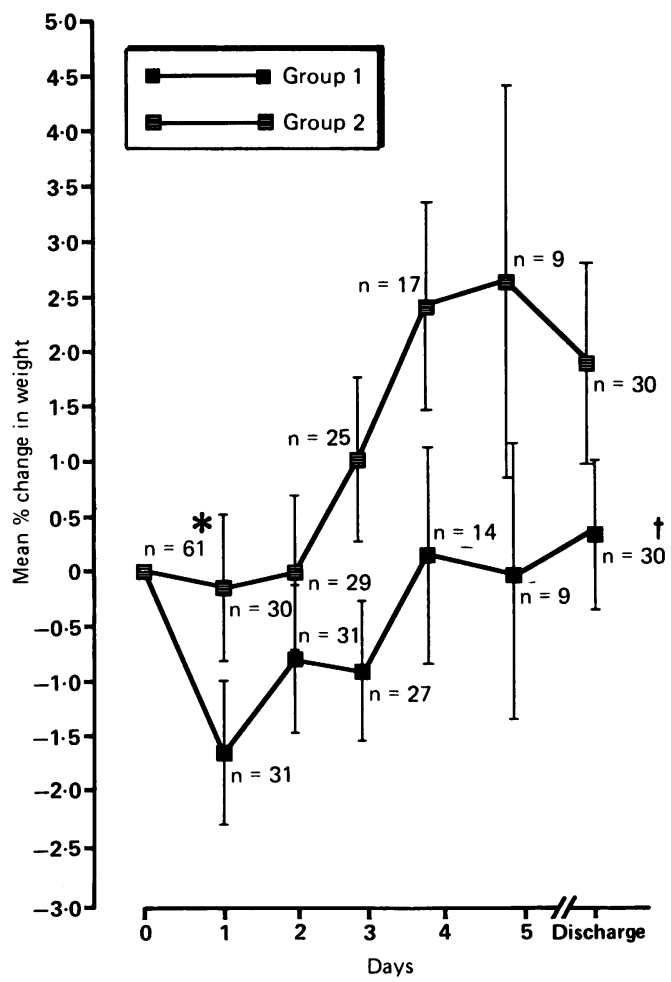

Mean $\%$ change in weight between the two groups. * One patient in group 1 did not have admission weight recorded so was excluded; tanother patient in group 1 did not have was excluded; fanother patient in group 1 did not have
discharge weight recorded so was excluded. Vertical bars indicate I SEM. There were no significant differences between the groups. dehydration and none required intravenous fluids:

Twenty six patients (42\%) had recurrence of diarrhoea within seven days of refeeding (table 2). They all settled satisfactorily with the introduction of lactose free soya based formula except one patient in group 2 who required an elemental feed (Pregestimil, Bristol-Myers) for a week before the diarrhoea stopped and lactose free soya based formula was reintroduced. Three patients in group 1 relapsed on refeeding without appreciable stool reducing sugars or evidence of other conditions leading to continued diarrhoea. On the basis of a satisfactory response to the lactose free soya based formula, two were presumed to have intolerance to cows' milk protein. The third patient was readmitted five days after refeeding, having been started on lactose free soya based formula 24 hours previously at home for presumed lactose intolerance. There was no significant difference in the incidence of lactose intolerance and no patient had recurrence of diarrhoea beyond seven days due to refeeding. There were no other factors associated with recurrence of diarrhoea such as age (less than 3 months), sex, ethnic origin, or treatment before admission with oral rehydration solution. Two other patients were readmitted with diarrhoea, one had a urinary tract infection and the other had a further episode of gastroenteritis due to rotavirus (no pathogen identified during first admission).

The figure shows the mean percentage weight gain of both groups from admission to day 5, and on discharge. Although group 1 tended to have greater initial weight loss this did not reach significance (Mann-Whitney U test) and both groups achieved satisfactory weight gain during their admission. All patients were above the third centile for weight.

The mean (SD) length of stay for group 1 was $4.3(1.7)$ days and for group 2 was $4.2(1.6)$ days. This was not significant, however; those patients who had a recurrence of diarrhoea remained in hospital for longer $(5 \cdot 2(1.8)$ days, $\mathrm{p}<0.0001)$ than those who had no recurrence $(3 \cdot 6(1 \cdot 1)$ days).

Details of gut pathogens identified are shown in table 3. The commonest pathogens were rotavirus and adenovirus serotype 40 and 41 . The viruses identified in the four other patients in group 1 were myxovirus, astrovirus, nonpolio enterovirus, and Norwalk agent. There was no association between any particular aetiological agent and recurrence of diarrhoea or lactose intolerance, although the numbers were small.

Table 3 Pathogens

\begin{tabular}{lll}
\hline & $\begin{array}{l}\text { Group } ~ \\
(n=32)\end{array}$ & $\begin{array}{l}\text { Group 2 } \\
(n=30)\end{array}$ \\
\hline $\begin{array}{l}\text { No pathogen identified } \\
\text { Pathogen identified: }\end{array}$ & $18(56 \%)$ & $17(57 \%)$ \\
Rotavirus & $14(44 \%)$ & $13(43 \%)$ \\
Adenovirus & 2 & 5 \\
Calicivirus & 2 & 4 \\
Salmonella spp & 1 & 0 \\
Campylobacter & 0 & 2 \\
Adenovirus/salmonella & 0 & 1 \\
Escherichia coli & 1 & 1 \\
Other viruses & 4 & 0 \\
\hline
\end{tabular}


There were no long term complications and most patients placed on the lactose free soya based formula were successfully weaned back onto formula cows' milk feeds within six weeks.

\section{Discussion}

Previous studies have shown gradual reintroduction of cows' milk to be unnecessary in infants over 6 months of age with acute gastroenteritis. ${ }^{3-5}$ A recent study came to the same conclusion in babies aged over 6 weeks. ${ }^{14}$ Our study is the first to report on gradual refeeding compared with abrupt refeeding in all babies below 6 months of age.

Gastroenteritis in this country is usually of mild to moderate severity, ${ }^{15}$ and our results show there is no advantage in gradually refeeding babies who present with mild to moderately severe gastroenteritis after rehydration. There is no difference in the effect on weight, duration of hospital stay, or recurrence of diarrhoea due to lactose intolerance. The incidence of lactose intolerance is high compared with previous studies $^{16}$ and rather surprising in view of the perceived decline of this condition in developed countries. ${ }^{12}$ In a similar study by Dugdale et al, ${ }^{4}$ however, in patients over 6 months of age, the incidence of recurrence of diarrhoea during admission or within seven days of discharge was $22 \%$ in a graduated refeeding group and $32 \%$ in an abrupt refeeding group. Trounce and Walker-Smith found an overall incidence of lactose intolerance of $7 \cdot 5 \%,{ }^{11}$ but $73 \%$ of those patients were below 6 months so a higher incidence might be expected in this age group.

We have successfully treated lactose intolerance in our patients with a lactose free soya based formula thus confirming the efficacy of temporary omission of lactose from the diet. ${ }^{16}$ Other authors have recommended repeated attempts at regrading with cows' milk feeds ${ }^{11}$; however, we would argue that this prolongs hospital stay unnecessarily when a simple, nutritionally adequate alternative is available. ${ }^{17}$ The risk of developing soya protein intolerance at about $15 \%$ for children with cows' milk protein intolerance ${ }^{1819}$ or of aluminium toxicity in the presence of impaired renal function ${ }^{20}$ would be the arguments against such an approach.

The overall incidence of identifiable pathogens in our patients is low, particularly rotavirus. In a study by Ellis and colleagues rotavirus was shown to be responsible for $35 \%$ of infantile gastroenteritis. ${ }^{21}$ In addition, Clostridium difficile toxin was found in $4.9 \%$ of their patients. We did not routinely screen for $C$ difficile toxin and the period of this study did not cover the peak of the rotavirus season, which occurs in the first four months of the year. ${ }^{22}$

Other studies have demonstrated an association between rotavirus infection and lactose intolerance, ${ }^{11} 1623$ a finding we did not confirm. As discussed above, however, the numbers in our study with rotavirus were particularly low.

See related articles on p 917 and p 939.
We recommend rapid refeeding in well nourished well hydrated babies with acute gastroenteritis. The usual approach in our unit is to refeed with the patients' own cows' milk formula or breast milk wherever possible. Recurrence of diarrhoea due to lactose intolerance can be appropriately treated by a lactose free soya based feed and in view of the high incidence of lactose intolerance in our study it may be worth considering refeeding all hospitalised babies under 6 months with such a feed. This is an area worthy of further examination which should include a comparison of continuation of the same feed with a lactose free soya based formula.

We gratefully acknowledge the assistance of Sister S Thompson and all nursing staff, ward 16, Monsall Hospital without whom this study would not have been possible. We also thank Dr V Hillier, department of medical computation, Manchester University Medical School for the statistical analysis.

1 Brown KH, Maclean WC. Nutritional management of acute diarrhoea: an appraisal of the alternatives. Pediatrics 1984; 73:119-25.

2 Chung AW, Viscorova B. The effect of early oral feeding versus early oral starvation on the course of infantile diarrhoea. $₹$ Pediatr 1948;33:14-22.

3 Rees L, Brook CGD. Gradual reintroduction of full-strength milk after acute gastroenteritis in children. Lancet 1979;i:

4 Dugdale A, Lovell S, Gibbs V, Ball D. Refeeding after acute gastroenteritis: a controlled study. Arch Dis Child 1982;57: 76-8.

5 Isolauri E, Vesihari T, Saha P, Viander M. Milk versus no milk in rapid refeeding after acute gastroenteritis. $\mathcal{F}$ Pediatr Gastroenterol Nutr 1986;5:254-61.

6 Wharton BA, Pugh RE, Taitz LS, Walker-Smith JA, Booth IW. Dietary management of gastroenteritis in Britain. $\mathrm{Br}$ Med f 1988;296:450-2.

7 World Health Organisation. Programme for control of diarrhoeal disease. Geneva: WHO, 1983:12-3. (Interim report WHO/CDD/844.14.)

8 Fox R. Pre-hospital management of infantile gastroenteritis. $\mathcal{F} R$ Coll Gen Pract (in press).

9 Lifshitz F, Coello-Ramirez P, Gutievvz-Topete G, GarnadoCornet MC. Carbohydrate intolerance in infants with diarrhoea. F Pediatr 1971;79:760-7.

10 Kumar Y, Chandrasehran R, Bhashar R. Carbohydrate intolerance associated with acute gastroenteritis. A prospective study of 90 well-nourished Indian infants. Clin Pediat (Phila) 1977;16:1123-7.

11 Trounce JQ, Walker-Smith JA. Sugar intolerance complicating acute gastroenteritis. Arch Dis Child 1985;60: 986-90.

12 Anonymous. What has happened to carbohydrate intolerance following gastroenteritis? Lancet $1987 ; \mathrm{i}: 23-4$.

13 Kerry KR, Anderson CM. A ward test for sugar in the faeces. Lancet 1964;i:981.

14 Conway SP, Ireson A. Acuté gastroenteritis in well nourished infants: comparison of four feeding regimes. Arch Dis Child 1989;64:87-91.

15 Ellis ME, Watson B, Mandal BK, Dunbar EM, Mokashi A. Contemporary gastroenteritis of infancy: clinical feature and pre-hospital management. Br Med f 1984;288:521-3. Davidson GP, Goodwin D, Robb TA. Incidence and duration of lactose malabsorption in children hospitalised with acute
enteritis: study in a well-nourished urban population. enteritis: study in a well-n
$\mathcal{f}$ Pediatr 1984:105:587-90.

17 Jung AL, Carr St. A soy protein formula and a milk based formula. Clin Pediatr (Phila) 1977;16:982-5.

18 Perkkio M, Savilhati E, Kuitunen P. Morphometric and immunohistochemical study of jejunal biopsies from hildren with intestinal soy allergy. Eur f Pediatr 1981;137 63-9.

19 Kuitunen P, Visakorpi JK, Savilahti E, Pelkonen P. Malabsorption syndrome with cows' milk intolerance. Arch Dis Child 1975;50:351-6.

20 Bishop N, McGraw $M$, Ward $M$. Aluminium in infant formulas. Lancet 1989;i:490.

21 Ellis ME, Watson B, Mandal BK, et al. Micro-organisms in gastroenteritis Arch Dis Child 1984;59:848-55.

22 Manchester Public Health Laboratory. Rotavirus in the North West region. Weekly report of infectious diseases (North West) 1989;89,25:1-4.

23 Hyams JS, Kranse PJ, Gleason PA. Lactose malabsorption following rotavirus infection in young children. 7 Pediat 1981;99:916-8 